\title{
Novel study designs to investigate the placebo response
}

\author{
Paul Enck ${ }^{1 *}$, Sibylle Klosterhalfen ${ }^{1,2}$ and Stephan Zipfel ${ }^{1}$
}

\begin{abstract}
Background: Investigating the size and mechanisms of the placebo response in clinical trials have relied on experimental procedures that simulate the double-blind randomized placebo-controlled design. However, as the conventional design is thought to elucidate drug rather than placebo actions, different methodological procedures are needed for the placebo response.

Methods: We reviewed the respective literature for trials designs that may be used to elucidate the size of the placebo response and the mechanisms associated with it.

Results: In general, this can be done by either manipulation the information provided to the subjects, or by manipulation the timing of the drug applied. Two examples of each strategy are discussed: the "balanced placebo design" (BDP) and the "balanced cross-over design" (BCD) and their variants are based on false information, while the "hidden treatment" (HT) and the "'delayed response test" (DRT) are based on manipulating the time of drug action. Since most such approaches include deception or incomplete information of the subjects they are suitable for patient only with authorized deception.
\end{abstract}

Conclusion: Both manipulating the information provided to subjects (BDP, DCD) or manipulating the timing of drug application (HT, DRT) allows overcoming some of the restrictions of conventional drug trials in the assessment of the placebo response, but they are feasible mostly in healthy subjects for ethical reasons.

Keywords: study design, experimental research, placebo

\section{Review}

\section{Placebo response and placebo effect}

Ever since the dawn of the first randomized placebocontrolled trials testing new drugs and treatments in the middle of the last century, and even before [1], placebo responses in clinical trials have given rise to discussion and concern regarding their mechanisms, and have usually been regarded as a nuisance or a barrier to a rational approach in modern drug development. High placebo responses have induced false expectations regarding drug efficacy and resulted in the refusal or withdrawal of drugs in some cases, e.g. neurokinins in the treatment of depression.

Not only do placebo responses in clinical trials impose significant limits to the testing of new compounds, but

\footnotetext{
* Correspondence: paul.enck@uni-tuebingen.de

'University Hospital Tübingen, Dept. of Psychosomatic Medicine, Tübingen, Germany

Full list of author information is available at the end of the article
}

they are also linked to the drug adherence and compliance of patients in such trials in a paradoxical way. Patients that adhered to medication instructions by more than $80 \%$ showed better survival in a coronary disease study, and poor drug adherence in a myocardial infarction survivor study was associated with a higher risk of mortality [2] irrespective of whether the active compound or a placebo was taken, and regardless of other potential risk factors. This has been attributed to the greater expectancies or beliefs, both in drug and placebo responders that the medication may be of help, although other factors, such as health behaviors, cannot be ruled out completely. These findings have certainly fostered the development of further experimental approaches to the placebo phenomenon [3].

Attempts to unravel the mechanisms of the placebo response in clinical trials have used meta-analytic approaches of the placebo arm of trials - with mixed results. The drug-placebo difference in randomized
C Biomed Central

(c) 2011 Enck et al; licensee BioMed Central Ltd. This is an Open Access article distributed under the terms of the Creative Commons Attribution License (http://creativecommons.org/licenses/by/2.0), which permits unrestricted use, distribution, and reproduction in any medium, provided the original work is properly cited. 
controlled trials has been reported to be around $40 \%$ in functional disorders [4] but lower in depression (29\%), bipolar mania (31\%) and migraine $(21 \%)[5,6]$. The reasons for these variable placebo effect rates are unknown but may include the sample size [4], the year of study [7], design characteristics [6], and recruitment pattern [8]. Meta-analyses can come to opposite conclusions on the same data set, e.g. with respect to the direction of the effects of the number of study visits on the placebo effect size $[9,10]$, but this may be due to data extraction errors that lead to false findings and conclusions [11]. Other contributing factors to the placebo response rate in clinical trials were: the origin of patients - response rates in migraine prophylaxis were higher in Europeans than in North Americans [6] - personal expectations [12] and the loss thereof, e.g. in Alzheimer's disease [13], the study center [14], and patient recruitment and physician training [8]. A genetic contribution to placebo responsiveness has been shown [15] but strong empirical evidence is still lacking.

Because of the difficulties to reliably identify placebo responders and predicting placebo response rates in clinical and experimental trials, different methodological attempts have been made to the way (novel) drugs are tested against placebo. At the same time, but to a varying degree, these and other designs have also be used to unravel some of the mechanisms behind the placebo response. This review will discuss experimental designs that may allow characterization and quantification the placebo response. We will introduce two distinctly different approaches to elucidate the mechanisms behind this response, i.e. by manipulating the information provided to participants and by manipulating the timing of drug action, and will present examples for both from the current literature.

Throughout this review we will use the following terminology: placebo response is the response observed in patients receiving a placebo treatment in a trial, which is measured by within-group changes. Placebo effect, in contrast, is the effect attributable to the placebo treatment after controlling for other non-specific or extraneous factors such as the natural history and regression to the mean; this is measured by the difference between a placebo group and a no-treatment control group in a trial [16]. Thus, the placebo response is expected to be larger than the placebo effect, and the difference between both is explained by other factors. Our review will not focus on designs for better discrimination between the drug and the placebo effect in clinical trials.

\section{Traditional designs}

The most traditional way to attempt to "control" for placebo response in clinical trials was the use of a crossover design, in which an individual patient serves as her/his own control, reducing the between-subject variability and the number of patients studied. Data from crossover trials can also be used to identify predictors of the placebo response in various clinical conditions.

This model was almost completely abolished due to the fact that blinding may be rather difficult in such studies $[17,18]$. Although "active placebos" that mimic the side effects of a compound without inducing its main effects have been used to avoid such problem [19], this approach can sometimes introduce bias into trials given that some "active placebos" may not be inert [18]. Another major limitation of the crossover design is the interference of learning effects: prior exposure to drug influences the effects of subsequent treatment and prior exposure to placebo may affect drug efficacy $[20,21]$.

Another conventional model to rule out placebo responses is the use of a placebo run-in phase prior to drug and placebo dispensing to identify and exclude placebo responders: Placebo responders tend to exhibit less severe symptoms during run-in [22-25], and to respond faster to treatment with symptom improvement [26] than patients in the drug arm. Drug-free run-in periods have also been used to identify individual and group characteristics of placebo responders. However, these results cannot be generalized across medical conditions $[24,27]$ since most of the variables that are regularly documented at study initiation are related to symptoms and disease characteristics rather than to individual personality traits or states [28]. Extensions of placebo runin periods are studies with multiple drug/placebo phases that alternate, with or without washout periods inbetween [29]. These models were more recently requested again by drug approval authorities to account for variable symptom courses and the alternation of symptom-free with relapse periods in many chronic diseases. It has, however, been shown that the placebo response in a first medication period does not reliably predict the response (to drug or placebo) in a second phase [30].

If being a placebo responder is a stable characteristic of an individual patient - which some of the published data question - study designs should take this into account by employing a design with multiple $(>2)$ crossovers between placebo and drug, and to randomize and individualize in a "single subject trials" (SST) the timing for run-in and run-out for each phase [31]. In theory, this should allow to reliably distinguish placebo responders from non-responders. However, multiple crossovers with randomly assigned treatment periods, with a complete random order or a random starting day may generate specific methodological problems and need new statistical models before being applicable in clinical drug testing. One such novel clinical model was tested recently in the therapy of Parkinson's Disease called the 
Delayed-Start Study Design (also named the randomized-start design) [32].

While all of these designs may be able to improve drug testing and the distinction between drug and placebo response, most of these designs are not able to characterize the nature of the placebo response and the mechanisms behind it. Even meta-analyses of the placebo arms of drug trials as discussed above will only allow describing potential predictors of the placebo response that need prospective validation in experimental or clinical settings.

\section{Experimental designs}

In laboratory research, a number of experimental designs have been employed that may help to identify and characterize predictors of the placebo response in the future. They have been generated by theoretical issues such as the "additive model" as discussed by Kirsch 2000 [33]. Some of these models have already been tested in laboratory settings, while others are based on theoretical considerations and wait for their empirical approval. Different from clinical trials, experimental designs allow control over some of the factors that are believed to drive the placebo response, e.g. the wording and timing of information provided [34], the gender and social status of the experimenter and the subject [35], their emotional state [36] and psychological and genetic traits $[15,37]$.

\section{The problem of the "additive-model" assumption}

Randomized and placebo-controlled clinical trials usually operate under the assumption that drug and placebo effects are additive in the drug arm of the study (Figure 1), thus subtracting the response in the placebo arm of the study from the response in the drug arm would allow to assess the "true" drug efficacy. This assumption is inherent in all current drug trials and is present also in most experimental studies.

This model has, however, been questioned [38]. One argument against the additive model is incomplete blinding with many drugs, so that patients/subjects may be aware of the experimental condition by taking adverse events into account. This would increase the placebo response in the drug group and reduce the placebo response in the placebo group. Recently, neurobiological evidence against the additive model has been provided [39] and is summarized elsewhere [40].

Therefore, Kirsch \& Weixel [38] and Kirsch [33] proposed the "balanced placebo design" as an answer to this open question.

\section{The balanced placebo design (BPD)}

The so-called "balanced placebo design" (BPD) was traditionally used in the testing for expectancy effects of frequently consumed everyday-drugs such as caffeine, nicotine and alcohol [41], recently also with drugs such as marijuana [42].

While one half of the study sample receives placebo and the other half the drug, half of each group is receiving correct information while the other half is receiving false information on the nature of their study condition (drug or placebo) immediately prior to drug testing, thus allowing to differentiate between the "true" drug response (those receiving the drug but are told they received placebo) and the true placebo response (those receiving placebo but are told they received the drug).

The "non-additive model" according to Kirsch [33] can be tested in the following way: If the difference between the drug response plus the placebo response and true drug response is unequal to the true placebo response, the non-additive assumption is correct.

A variant of the BPD is the "half BPD" in which all subjects are given placebos, but half of them receive information that they receive the drug - this is the most common design in current placebo research, as it does not require approval for performing a drug study. However, effective double blinding of such as study is difficult unless - as in a recent test in our laboratory - the subjects and the experimenter(s) conducting the study are made to believe that they participate in a full BPD.

As is evident, BPD studies imply deception of the subjects [43]. This limits its suitability and acceptance outside the laboratory and in patients for ethical reasons [44] unless the proposed "authorized deception" is implemented. It has recently been shown in an experimental placebo analgesia trial that authorized deception will not corrupt the data collection [45].

One of the pitfalls of the BPD is the fact that all subjects are informed (either correctly or falsely) prior to testing whether and what they have received. In sceptical subjects (especially medical students), this may raise doubts about the truth of the information provided and may require additional measures, such as a reliable "cover story" about the rational why the information is given at all. This is usually done by informing them that once the drug is active, the information whether and what they received may no longer be relevant - however, the subjects' acceptance of such information is difficult to prove prior to the test, and its testing afterwards may be subject to another bias.

\section{The balanced cross-over design (BCD)}

In an attempt to overcome the serious limitations of the $\mathrm{BPD}$, we designed another strategy that may account for some of the BDP limitations. In this case, subjects are divided into four groups, and all are told they participate in a conventional randomized double-blinded and placebo-controlled crossover trial, in which they will receive both the drug and the placebo at two different occasions 


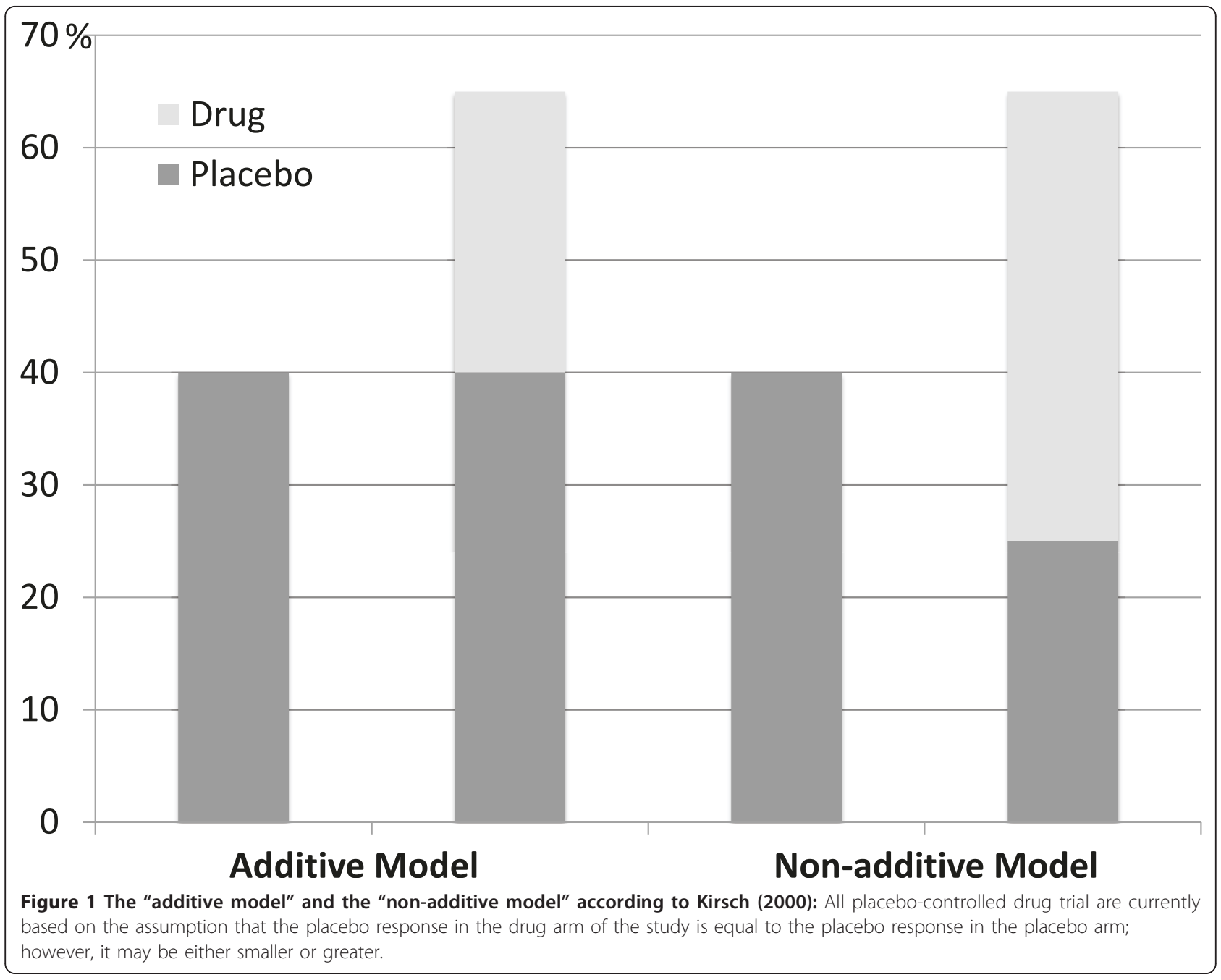

in a randomized and double-blinded order. However, only group 2/3 will be exposed to drug and placebo in a balanced way, that is half the subjects will receive the drug first and the placebo at the second occasion, while the other half will receive first placebo and then the drug. Group 1 will receive drug - drug, and Group 4 will receive placebo - placebo instead (Figure 2).

In this case, Groups 2 and 3 represent the conventional drug trial assuming the "additive model" for drug and placebo response. In Group 1, the minimal value of both measures represents the "true" drug response, and the difference between both is the expectancy component of the drug response. In Group 4, the maximum value should represent the "true" placebo response; and the difference between both values should be the expectancy component of the placebo response. Comparing these expectancy effects between groups 1 and 4 allows to test whether the expectancy component of the placebo response is equal under drug and placebo condition - which is the assumption of the "additive model".
The BCD has one important methodological limitation: As with other crossover designs, interference of learning effects need to be kept in mind [20,21], and any adaptation or habituation between measurement 1 and measurement 2 should be minimized, e.g. by increasing the time interval between the two. Its ethical limitations (deception) are similar to those of the BPD with the exception, that subjects may receive a drug twice but expect it to receive only once - any risk involved in such a repetition of drug application would exclude the BCD from use, and it can only be used in patients when the deception is authorized [43].

To our knowledge, this design has not been used so far in any research, whether related to drug or to the placebo response.

\section{"Hidden treatment" according to Benedetti}

While most designs and attempts to modify the response to a drug and explore the placebo response (as those discussed above) manipulate the information 


\begin{tabular}{|c|c|c|c|}
\hline & & \multicolumn{2}{|c|}{ First medication application } \\
\hline & & drug & placebo \\
\hline $\begin{array}{c}\text { Second } \\
\text { medication } \\
\text { application }\end{array}$ & placebo & $3:$ drug - placebo & 4: placebo placebo \\
\cline { 2 - 4 } & & $1:$ drug - drug & 2: placebo - drug \\
\hline
\end{tabular}

Figure 2 The "balanced cross-over design" (BCD): All subjects are told they participate in a double-blind cross-over design study and will receive both drug and placebo; this is true for groups 2 and 3, while in groups 1 and 4 they receive drug - drug and placebo - placebo, respectively.

provided to the subjects, a few others, such as the "hidden treatment" paradigm [46] manipulate the timing of the drug action to identify whether and to what degree the placebo response can be elucidated.

Hidden treatment (HT) or covert treatment is an option that may be specifically useful for the test of drug effects in acute and highly symptomatic conditions such as with postoperative pain [47], anxiety, and motor dysfunction in Parkinson's disease [48,49]. It resembles some of the features of the "single subject trials" [31]. In case of HT, the patient receives a drug unnoticed in terms of timing and dosage, and the drug effect (or its missing action) can be determined independent of the patient's expectations. Benedetti and colleagues demonstrated that under these circumstances drugs commonly believed to have analgesic properties such as CCKantagonists failed to show any anti-nociceptive effects [50]. Evidently, HT can only be applied with the patient being fully informed prior to the test that she/he will receive the drug in any case but will not be informed about when the drug is provided, otherwise the approach may raise other ethical concerns [51], especially with the test of novel compounds of unknown properties.

\section{The "delayed response" test}

A very unique approach based on such an assumption that has - to our knowledge - never been explored in any placebo testing is the following: Assume that a drug can elicit its action at a predefined time point hours after ingestion, either via a coating technology [52] or a radio-transmitted mechanical capsule technology [53] for controlled release of the compound; such technology has been used in many clinical conditions such as diabetes, Alzheimer dementia and other conditions. In this case, a three-arm design (Figure 3) would allow a very elegant prove of the additive versus non-additive model of the placebo response.

All subjects receive the same information that they will receive either a drug or placebo in a double-blinded fashion, and no information is given about the timing of drug action; instead, a rational ("cover story") is provided for prolonged drug action monitoring, e.g. for 24 hours.

Group 1 will receive the drug with immediate action, group 2 the respective placebo. Group 3 receives the delayed response medication, e.g. with drug release after 12 hours. To confirm the "non-additive model" (P1 $\neq$ $\mathrm{P} 2), \mathrm{M} 1+\mathrm{P} 1 \neq \mathrm{M} 2+\mathrm{P} 3$, with $\mathrm{P} 3=\mathrm{P} 2$ and $\mathrm{M} 1=\mathrm{M} 2$.

A variant of such a design that intended to elucidate the drug response in a clinical trial in Parkinson's Disease was recently described [32]. While this has never been used in a laboratory setup for assessment of the placebo response, preliminary approval of the underlying hypothesis may be drawn from clinical studies that have used the delayed release technology in the treatment of patients, e.g. in 5-ASA treatment of chronic inflammatory bowel diseases [54]: in these studies, the placebo response should be overall lower as compared to immediate release medication. Unfortunately, the number of placebo-controlled studies using such technology is so far rather low to allow a reliable metaanalytic comparison.

\section{Conclusions}

Investigating the size and mechanisms of the placebo response in different medical conditions has relied on experimental procedures that simulate the double-blind 


\section{Group 1 Group 2 Group 3}
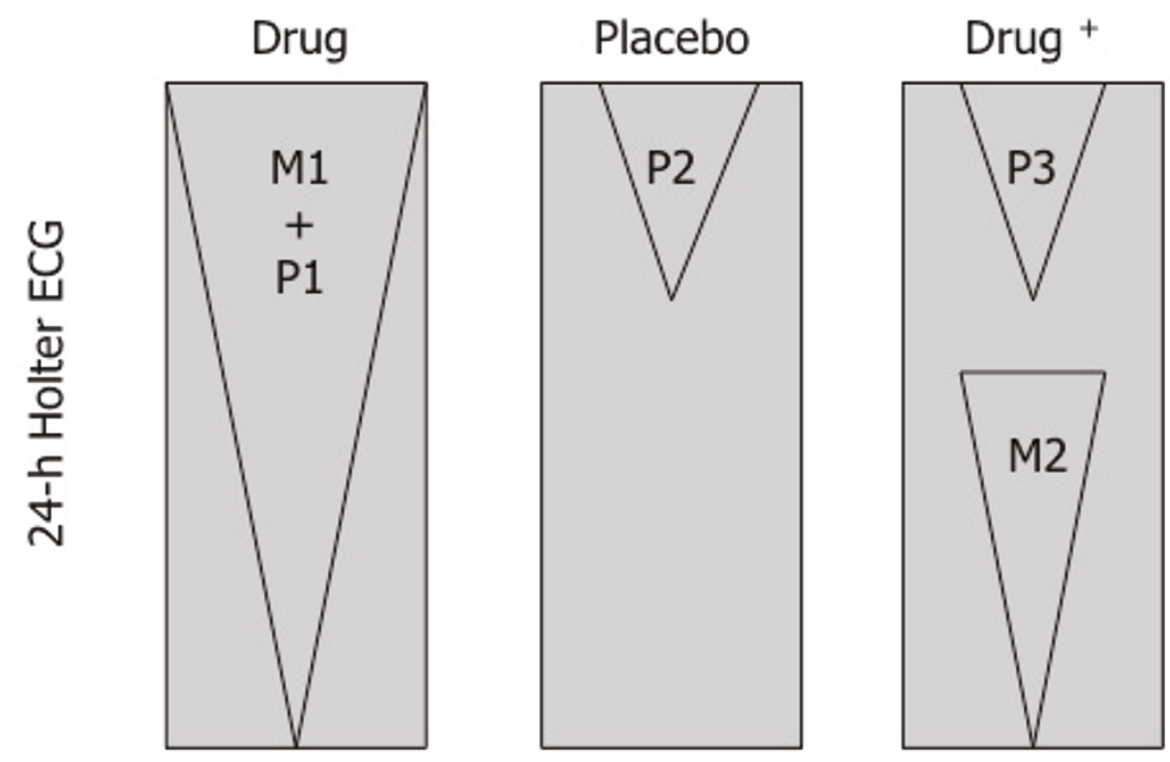

\section{+: with a $12 \mathrm{~h}$ delayed response on the target variable}

\section{Assumption: $\mathrm{M} 1=\mathrm{M} 2$ und $\mathrm{P} 2=\mathrm{P} 3 \quad$ Hypothesis: $\mathrm{M} 1+\mathrm{P} 1 \neq \mathrm{M} 2+\mathrm{P} 3$}

Figure 3 The "delayed response test" (DRT) design: The "additive model" by Kirsch (2000) assumes that P1 = P2. Under the further assumptions that $M 1=M 2$ and $P 2=P 3$, the hypothesis of the "additive model" is falsified if $(M 1+P 1 \neq M 2+P 3)$.

randomized placebo-controlled design of clinical trials. However, as the conventional design is thought to elucidate drug rather than placebo actions, different methodological procedures are needed for the placebo response. In general, this can be done by either manipulation the information provided to the subjects, or by manipulation the timing of the drug applied. Two examples of each strategy are discussed: the "balanced placebo design" (BDP) and the "balanced cross-over design" (BCD) and their variants are based on false information provided, while the "hidden treatment" (HT) strategy and the "delayed response test" (DRT) are based on altering the timing of drug action. While most such approaches include deception of the subjects this limitation can be overcome by implementing "authorized deception".

\section{Acknowledgements}

We are indebted to a group of young psychosomatic residents (Marc-Andre Wulf, Anne Grimm, Ulrike Dinger, Jonas Tesarz and others) for their unique design called "delayed response test" here that was developed during a group session of the 2009/2010 "Carus Training Program" of the German College of Psychosomatic Medicine (DKPM).

Supported by a grant from Volkswagen Foundation (I/83 805) to PE.

\section{Author details}

'University Hospital Tübingen, Dept. of Psychosomatic Medicine, Tübingen, Germany. ${ }^{2}$ University of Düsseldorf, Institute for Clinical Neurobiology and Medical Psychology, Düsseldorf, Germany.

\section{Authors' contributions}

PE and SK developed the idea for this manuscript, reviewed the respective literature, discussed the potentials of alternatives to traditional trial designs, PE wrote the manuscript, and SZ helped writing the manuscript. All authors read and approved the final manuscript.

\section{Competing interests}

The authors declare that they have no competing interests.

Received: 14 September 2010 Accepted: 10 June 2011

Published: 10 June 2011

\section{References}

1. Hill $A B$ : Suspended judgment: memories of the British streptomycin trial in tuberculosis. The first randomized clinical trial. Controlled Clinical Trials 1990, 11:77-79.

2. Coronary Drug Project Research Group: Influence of adherence to treatment and response of cholesterol on mortality in the coronary drug project. N Engl J Med 1980, 303:1038-1041. 
3. Enck P, Benedetti F, Schedlowski M: New insights into the placebo and nocebo responses. Neuron 2008, 59:195-206.

4. Enck P, Klosterhalfen S: The placebo response in functional bowel disorders: perspectives and putative mechanisms. Neurogastroenterol Motil 2005, 17:325-31.

5. Sysko R, Walsh BT: A systematic review of placebo response in studies of bipolar mania. J Clin Psychiatry 2007, 68:1213-127.

6. Macedo A, Banos JE, Farre M: Placebo response in the prophylaxis of migraine: A meta-analysis. Eur J Pain 2008, 12:68-75.

7. Walsh BT, Seidman SN, Sysko R, Gould M: Placebo response in studies of major depression - variable, substantial, and growing. JAMA 287:1840-1847.

8. Kobak KA, Kane JM, Thase ME, Nierenberg AA: Why do clinical trials fail? The problem of measurement error in clinical trials: time to test new paradigms? J Clin Psychopharmacol 2007, 27:1-5

9. Pitz $M$, Cheang $M$, Bernstein CN: Defining the predictors of the placebo response in irritable bowel syndrome. Clin Gastroenterol Hepatol 2005, 3:237-247.

10. Patel SM, Stason WB, Legedza A, Ock SM, Kaptchuk TJ, Conboy L, Canenguez K, Park JK, Kelly E, Jacobson E, Kerr CE, Lembo AJ: The placebo effect in irritable bowel syndrome trials: a meta-analysis. Neurogastroenterol Motil 2005, 17:332-340.

11. Gøtzsche PC, Hróbjartsson A, Maric K, Tendal B: Data extraction errors in meta-analyses that use standardized mean differences. JAMA 2007, 298:430-437.

12. Linde K, Witt CM, Streng A, Weidenhammer W, Wagenpfeil S, Brinkhaus B, Willich SN, Melchart D: The impact of patient expectations on outcomes in four randomized controlled trials of acupuncture in patients with chronic pain. Pain 2007, 128:264-271.

13. Benedetti F, Arduino C, Costa S, Vighetti S, Tarenzi L, Rainero I, Asteggiano G: Loss of expectation-related mechanisms in Alzheimer's disease makes analgesic therapies less effective. Pain 2006, 121:133-144.

14. Ondo WG: Placebo response in Parkinson trials using patient diaries: sites do matter. Clin Neuropharmacol 2007, 30:301-304.

15. Furmark T, Appel L, Henningsson S, Ahs F, Faria V, Linnman C, Pissiota A, Frans O, Bani M, Bettica P, Pich EM, Jacobsson E, Wahlstedt K, Oreland L Långström B, Eriksson E, Fredrikson M: A link between serotonin-related gene polymorphisms, amygdala activity, and placebo-induced relief from social anxiety. J Neurosci 2008, 28:13066-13074.

16. Ernst $\mathrm{E}$, Resch KL: Concept of true and perceived placebo effects. BMJ 1995, 311:551-553

17. Boutron I, Estellat C, Guittet L, Dechartres A, Sackett DL, Hróbjartsson A, Ravaud P: Methods of blinding in reports of randomized controlled trials assessing pharmacologic treatments: a systematic review. PLOS Med 2006, 3:e425.

18. Machado LA, Kamper SJ, Herbert RD, Maher CG, McAuley JH: Imperfect placebos are common in low back pain trials: a systematic review of the literature. Eur Spine J 2008, 17:889-904.

19. Edward SJ, Stevens AJ, Braunholtz DA, Lifford RJ, Swift T: The ethics of placebo-controlled trials: a comparison of inert and active placebo controls. World J Surg 2005, 29:610-614.

20. Suchman AL, Ader R: Classic conditioning and placebo effects in crossover studies. Clin Pharmacol Ther 1992, 52:372-377.

21. Colloca L, Benedetti F: How prior experience shapes placebo analgesia. Pain 2006, 124:126-133.

22. Bridge JA, Birmaher B, lyengar S, Barbe RP, Brent DA: Placebo response in randomized controlled trials of antidepressants for pediatric major depressive disorder. Am J Psychiatry 2008, 166:42-49.

23. Kirsch I, Deacon BJ, Huedo-Medina TB, Scoboria A, Moore TJ, Johnson BT: Initial severity and antidepressant benefits: a meta-analysis of data submitted to the Food and Drug Administration. PLoS Med 2008, 5:e45.

24. Enck $P$, Vinson B, Malfertheiner $P$, Zipfel $S$, Klosterhalfen S: Placebo effects in functional dyspepsia - reanalysis of trial data. Neurogastroenterol Moti 2009, 21:370-377.

25. Philip G, Swern AS, Smugar SS, Pearlman DS: Baseline predictors of placebo response in exercise-induced bronchoconstriction (EIB): pooled regression analysis from three studies of montelukast in EIB. J Asthma 2010, 47:935-941.

26. Gomeni R, Merlo-Pich E: Bayesian modelling and ROC analysis to predict placebo responders using clinical score measured in the initial weeks of treatment in depression trials. Br J Clin Pharmacol 2007, 63:595-613.
27. Talley NJ, Locke GR, Lahr BD, Zinsmeister AR, Cohard-Radice M, D'Elia TV Tack J, Earnest DL: Predictors of the placebo response in functional dyspepsia. Aliment Pharmacol Ther 2006, 23:923-936.

28. Hyland ME, Whalley B, Geraghty AW: Dispositional predictors of placebo responding: a motivational interpretation of flower essence and gratitude therapy. J Psychosom Res 2007, 62:331-340.

29. Kleveland PM, Larsen S, Sandvik L, Kristensen P, Johannessen T, Hafstad PE, Sandbakken P, Løge I, Fjøsne U, Petersen H: The effect of cimetidine in non-ulcer dyspepsia. Experience with a multi-cross-over model. Scand J Gastroenterol 1985, 20:19-24.

30. Tack J, Müller-Lissner S, Bytzer P, Corinaldesi R, Chang L, Viegas A, Schnekenbuehl S, Dunger-Baldauf C, Rueegg P: A randomised controlled trial assessing the efficacy and safety of repeated tegaserod therapy in women with irritable bowel syndrome with constipation. Gut 2005, 54:1707-1713.

31. Madsen $L G$, Bytzer P: Review article: Single subject trials as a research instrument in gastrointestinal pharmacology. Aliment Pharmacol Ther 2002, 16:189-196.

32. D’Agostino RB: The delayed-start study design. N Engl J Med 2009, 361:1304-1306

33. Kirsch I: Are drug and placebo effects in depression additive? Biol Psychiatry 2000, 47:733-735.

34. Flaten $\mathrm{M}$, Simonsen $\mathrm{T}$, Olsen $\mathrm{H}$ : Drug-related information generates placebo and nocebo responses that modify the drug response. Psychosom Med 1999, 61:250-255.

35. Klosterhalfen S, Kellermann S, Braun S, Kowalski A, Schrauth M, Zipfel S, Enck P: Gender and the nocebo response following conditioning and expectancy. J Psychosom Res 2009, 66:323-328.

36. Rakel DP, Hoeft TJ, Barrett BP, Chewning BA, Craig BM, Niu M: Practitioner empathy and the duration of the common cold. Family Med 2009, 41:494-501.

37. Leuchter AF, McCracken JT, Hunter AM, Cook IA, Alpert JE: Monoamine Oxidase A and Catechol-O-Methyltransferase functional polymorphisms and the placebo response in major depressive disorder. J Clin Psychopharmacol 2009, 29:372-377.

38. Kirsch I, Weixel $\sqcup$ : Double-blind versus deceptive administration of a placebo. Behav Neurosci 1988, 102:319-323.

39. Petrovic P, Kalso E, Petersson KM, Andersson J, Fransson P, Ingvar M: A prefrontal non-opioid mechanism in placebo analgesia. Pain 2010 150:59-65.

40. Enck P, Weimer K, Horing B, Klosterhalfen S, Zipfel S: Placebo effects in clinical trials - more questions than answers. Phil Trans Roy Soc B 2011 366:1889-1895.

41. Rohsenow DJ, Marlatt GA: The balanced placebo design: methodological considerations. Addict Behav 1981, 6:107-122.

42. Metrik J, Rohsenow DJ, Monti PM, McGeary J, Cook TA, de Wit H, Haney M, Kahler CW: Effectiveness of a marijuana expectancy manipulation: Piloting the balanced-placebo design for marijuana. Exp Clin Psychopharmacol 2009, 17:217-225.

43. Miller FG, Wendler D, Swartzman LC: Deception in research on the placebo effect. PLoS Med 2005, 2:e262.

44. Ehni HJ, Wiesing U: International ethical regulations on placebo-use in clinical trials: a comparative analysis. Bioethics 2008, 22:64-74.

45. Martin AL, Katz J: Inclusion of authorized deception in the informed consent process does not affect the magnitude of the placebo effect for experimentally induced pain. Pain 2010, 149:208-215.

46. Colloca L, Lopiano L, Lanotte M, Benedetti F: Overt versus covert treatment for pain, anxiety, and Parkinson's disease. Lancet Neurol 2004 3:679-684

47. Levine JD, Gordon NC, Smith R, Fields HL: Analgesic responses to morphine and placebo in individuals with postoperative pain. Pain 1981, 10:379-389.

48. Benedetti F, Colloca L, Lanotte M, Bergamasco B, Torre E, Lopiano L: Autonomic and emotional responses to open and hidden stimulations of the human subthalamic region. Brain Res Bull 2004, 63:203-211.

49. Lanotte M, Lopiano L, Torre E, Bergamasco B, Colloca L, Benedetti F: Expectation enhances autonomic responses to stimulation of the human subthalamic limbic region. Brain Behav Immun 2005, 19:500-509.

50. Colloca L, Benedetti F: Placebo and painkillers: is mind as real as matter? Nature Rev Neurosci 2005, 5:545-525. 
51. Machado L: Problems with the 'open-hidden' paradigm: the debate is still open and the answer is still hidden. Pain 2005, 117:240-241.

52. Behzadi SS, Toegel S, Viernstein H: Innovations in coating technology. Recent Pat Drug Deliv Formul 2008, 2:209-230.

53. Twomey K, Marchesi JR: Swallowable capsule technology: current perspectives and future directions. Endoscopy 2009, 41:357-362.

54. Fernandez-Becker NQ, Moss AC: Improving delivery of aminosalicylates in ulcerative colitis: effect on patient outcomes. Drugs 2008, 68:1089-1103.

Pre-publication history

The pre-publication history for this paper can be accessed here:

http://www.biomedcentral.com/1471-2288/11/90/prepub

doi:10.1186/1471-2288-11-90

Cite this article as: Enck et al:: Novel study designs to investigate the placebo response. BMC Medical Research Methodology 2011 11:90.

\section{Submit your next manuscript to BioMed Central} and take full advantage of:

- Convenient online submission

- Thorough peer review

- No space constraints or color figure charges

- Immediate publication on acceptance

- Inclusion in PubMed, CAS, Scopus and Google Scholar

- Research which is freely available for redistribution

Submit your manuscript at www.biomedcentral.com/submit 